doi:10.1016/j.chemosphere.2005.12.022

Copyright (c) 2005 Elsevier Ltd All rights reserved.

\title{
Dioxin and dioxin-like PCB exposure of non-breastfed Dutch infants
}

\author{
P.J.M. Weijs ${ }^{a}{ }^{*}$, M.I. Bakker ${ }^{b}$, K.R. Korver ${ }^{a}$, K. van Goor Ghanaviztchi ${ }^{a}$ and \\ J.H. van Wijnenc
}

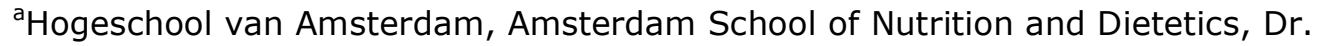
Meurerlaan 8, 1067 SM Amsterdam, The Netherlands

${ }^{\mathrm{b}}$ Centre for Substances and Integrated Risk Assessment, National Institute of Health and Environment, Bilthoven, The Netherlands

${ }^{\mathrm{c}}$ Environmental Medicine, Municipal Health Service Amsterdam, Amsterdam, The Netherlands

Received 28 May 2005; revised 24 November 2005; accepted 4 December 2005. Available online 25 January 2006.

\begin{abstract}
The exposure of humans to PCDD/Fs (polychlorinated dibenzo- $p$-dioxins and dibenzofurans) and dioxin-like PCBs (dl-PCBs, i.e. polychlorinated non-ortho and mono-ortho biphenyls) occurs predominantly via the intake of food. Young children have a relatively high intake of these substances, due to their high food consumption per kilogram body weight. As the exposure of non-breastfed infants to these compounds has not been assessed before in The Netherlands, we studied the dietary intake of 17 PCDD/Fs and 11 dioxin-like PCBs in 188 Dutch nonbreastfed infants between 4 and 13 months. The food intake of the infants was assessed by a 2-d food record. From these data PCDD/F and dioxin-like PCB intake was calculated using PCDD/F and dioxin-like PCB concentrations of food products sampled in 1998/1999 in The Netherlands. The long-term PCDD/F and dioxin-like PCB exposure of the infants was calculated using the statistical exposure model (STEM). For infants of 5 months the chronic exposure to PCDD/F and dioxin-like PCB was $1.1 \mathrm{pg}$ WHO-TEQ (toxic equivalents) per kilogram body weight (bw) per day (95th percentile: $1.7 \mathrm{pg}$ WHO-TEQ/ $\mathrm{kg}$ bw $\cdot \mathrm{d}$ ), which mainly originated from infant formula and vegetables and increased to $2.3 \mathrm{pg}$ WHO$\mathrm{TEQ} / \mathrm{kg}$ bw $\cdot \mathrm{d}$ (95th percentile $3.7 \mathrm{pg}$ WHO-TEQ/ $\mathrm{kg}$ bw $\cdot \mathrm{d}$ ) for infants just over 1 year old eating the same food as their parents. The percentage of formula-fed infants with an exposure exceeding the TDI of $2 \mathrm{pg}$ WHO-TEQ/kg bw $\cdot \mathrm{d}$ was $5 \%$ at 5 months, $49 \%$ at 9 months and $64 \%$ at 12 months.
\end{abstract}

Keywords: Polychlorinated dienzo- $p$-dioxin and dibenzofuran (PCDD/F); Dioxinlike PCB; Exposure; Infant feeding; Complementary foods

\section{Introduction}

Exposure to dioxins (polychlorinated dibenzo- $p$-dioxins and dibenzofurans) and dioxin-like PCBs (dl-PCBs, i.e. polychlorinated non-ortho and mono-ortho biphenyls) occurs predominantly via animal fats in the diet. Infants have a relatively high intake of these substances, due to the high food consumption per kilogram body weight. Breastfed infants have the highest intake of PCDD/Fs and 
dioxin-like PCBs, since breast milk contains relatively high concentrations of these compounds (Van Leeuwen et al., 2000). Exposure assessments of PCDD/Fs and dioxin-like PCBs have been made for breastfed infants in Europe and North America (Schecter et al., 1994, Brouwer et al., 1998 and Hoover, 1999). In addition to the intake of PCDD/Fs by breastfed infants, the intake by formula-fed infants from the UK and the United States was estimated (Schecter et al., 1994 and Food Standards Agency, 2004a) as well as intake by commercial baby foods (Food Standards Agency, 2004b). However, no complete dietary PCDD/Fs intake data, including either formula, commercial and non-commercial baby food, is available for infants.

Dietary fat intake and saturated fat intake, mainly from animal fat sources, tended to decrease in the general population between Dutch National Food Survey 1987-1988 and 1998 (Netherlands Nutrition Centre, 1998). In addition, the concentrations of PCDD/Fs and dioxin-like PCBs in the majority of the foodstuffs in The Netherlands have decreased since the seventies (Baars et al., 2004). Indeed in The Netherlands the exposure to dietary PCDD/Fs and dioxinlike PCBs has decreased since that time period (Baars et al., 2004). Whereas for the Dutch population the intake of these substances was estimated regularly since the seventies, for the last time in 2001 (Freijer et al., 2001 and Baars et al., 2004), intake estimates for young infants (during their first year of life) were not available. Therefore, in the present study the dietary exposure to PCDD/F and dioxin-like PCB of non-breastfed Dutch infants between 4 and 13 months of age is assessed.

\section{Materials and methods}

\subsection{Subjects}

Parents/care takers (referred to as 'parents') of infants have been approached by mail in March 2001. Addresses were obtained from a publisher of magazines aimed at parents of very small children. The addresses were nation-wide, but selected for the age groups $4,6,8,10$, and 12 months.

\subsection{Dietary intake}

By means of a two day food record the parents provided information on actual consumption of food in portions, or weighed if necessary. Parents were specifically asked to subtract spilled or not consumed amounts. Portion sizes were translated into weight by standard portion sizes used in The Netherlands (Donders-Engelen et al., 1997). Food weights were then multiplied by actual contents of both nutrients and pg TEQ for PCDD/F and dioxin-like PCB per $100 \mathrm{~g}$ food by using the Dutch Food Composition Table (NEVO Foundation, 2001). For foods that could not be translated to existing NEVO codes, mostly vegetables and meals in a jar, the PCDD/F and dioxin-like PCB concentration was calculated using data on the concentrations in ingredients.

\subsection{PCDD/Fs and dioxin-like PCB exposure}

First, 807 food products described in the NEVO table were assigned PCDD/F and dioxin-like PCB levels in pg TEQ per kilogram of food product, accounting for the percentage of fat in the food as it is eaten. The levels were established by the Institute of Public Health and the Environment (RIVM) and the Institute of Food Safety (RIKILT) in The Netherlands (Freijer et al., 2001 and Baars et al., 2004). These data were derived from measured levels in 16 food groups, which were composed of in total 70 fat-containing food-products and 21 vegetables 
purchased in The Netherlands in 1998/1999. Seventeen PCDD/Fs and eleven dioxin-like PCBs were analysed (for congeners and their TEFs see Table 1 ). The concentration levels are lower bound values, i.e. if a congener was not detected in a sample it was assigned the value 0 . For each food group two composite samples ( $n$ of composite is 10 ) were analysed and the average value was used in the intake calculation. We did not consider the range of measured concentrations in a food category since our interest is in long-term intake. Since for long-term exposure it is expected that concentration variations level out, average concentrations are sufficient for the calculation of the intake. The relative standard deviation of the two analyses per food group was between $5 \%$ and $103 \%$ (mean value $29 \%$ ). If concentrations were not available for specific foods then the PCDD/F and dioxin-like PCB level was calculated on the basis of amount and origin of the fat content in the food product (Freijer et al., 2001).

Table 1.

Analysed compounds and toxic equivalency factors to express the toxicity of mixtures of PCDDs, PCDFs and dioxin-like PCBs in toxic equivalents of 2,3,7,8TCDD, as used in the current work (Van den Berg et al., 1998)

\begin{tabular}{|l|l|}
\hline Compounds & WHO-TEF 1998 \\
\hline$P C D D s$ and PCDFs & 1 \\
\hline $2,3,7,8-\mathrm{TCDD}$ & 1 \\
\hline $1,2,3,7,8-\mathrm{PeCDD}$ & 0.1 \\
\hline $1,2,3,4,7,8-\mathrm{HxCDD}$ & 0.1 \\
\hline $1,2,3,6,7,8-\mathrm{HxCDD}$ & 0.1 \\
\hline $1,2,3,7,8,9-\mathrm{HxCDD}$ & 0.01 \\
\hline $1,2,3,4,6,7,8-\mathrm{HpCDD}$ & 0.0001 \\
\hline $0 \mathrm{CDD}$ & 0.1 \\
\hline $2,3,7,8-\mathrm{TCDF}$ & 0.05 \\
\hline $1,2,3,7,8-\mathrm{PeCDF}$ & 0.5 \\
\hline $2,3,4,7,8-\mathrm{PeCDF}$ & 0.1 \\
\hline $1,2,3,4,7,8-\mathrm{HxCDF}$ & 0.1 \\
\hline $1,2,3,6,7,8-\mathrm{HxCDF}$ & 0.1 \\
\hline $1,2,3,7,8,9-\mathrm{HxCDF}$ & 0.1 \\
\hline $2,3,4,6,7,8-\mathrm{HxCDF}$ & 0.01 \\
\hline $1,2,3,4,6,7,8-\mathrm{HpCDF}$ & 0.01 \\
\hline $1,2,3,4,7,8,9-\mathrm{HpCDF}$ & 0.0001 \\
\hline OCDF & \\
\hline & \\
\hline Non-ortho PCBs & \\
\hline 3,3 ',4,4'-CB(77) & 0001 \\
\hline
\end{tabular}




\begin{tabular}{|l|l|}
\hline Compounds & WHO-TEF 1998 \\
\hline $3,3^{\prime}, 4,4^{\prime}, 5-\mathrm{CB}(126)$ & 0.1 \\
\hline $3,3^{\prime}, 4,4^{\prime}, 5,5^{\prime}-\mathrm{CB}(169)$ & 0.01 \\
\hline & \\
\hline Mono-ortho PCBs & \\
\hline $2,3^{\prime} 3^{\prime}, 4^{\prime}, 4^{\prime}-\mathrm{CB}(105)$ & 0.0001 \\
\hline $2,3^{\prime}, 4^{\prime} 4^{\prime}, 5-\mathrm{CB}(114)$ & 0.0005 \\
\hline $2,3^{\prime}, 4,4^{\prime}, 5-\mathrm{CB}(118)$ & 0.0001 \\
\hline $2,3,4^{\prime} 4^{\prime}, 5-\mathrm{CB}(123)$ & 0.0001 \\
\hline $2,3^{\prime}, 3^{\prime}, 4^{\prime}, 4^{\prime}, 5-\mathrm{CB}(156)$ & 0.0005 \\
\hline $2,3,3^{\prime}, 4,4^{\prime}, 5^{\prime}-\mathrm{CB}(157)$ & 0.0005 \\
\hline $2,3^{\prime}, 4,4^{\prime}, 5,5^{\prime}-\mathrm{CB}(167)$ & 0.00001 \\
\hline $2,3^{\prime} 3^{\prime}, 4^{\prime}, 4^{\prime}, 5,5^{\prime}-\mathrm{CB}(189)$ & 0.0001 \\
\hline
\end{tabular}

The average concentrations of the food products were combined with the individual food consumption data from the food survey. For each individual the intake was computed for the two consecutive days considered in the survey. The resulting distribution shows the variation in short-term intake, but is unsuitable for an assessment of the long-term intake, which is required for a comparison with the tolerable daily intake (TDI). A distribution of long-term averaged intakes would be considerably narrower than the distribution of daily intakes, because within-subject variations level out. To distinguish the variation between individuals from the daily fluctuations in consumption, we used the statistical exposure model (STEM) (Slob, 1993) which estimates the mean dietary intake as a function of age. It combines regression analysis on age by fitting an appropriate curve to the data with a nested analysis of variance. The individual daily intakes are assumed to be log normally distributed.

\section{Results}

\subsection{Infants and their parents}

The survey data range from 1 April 2001 to 8 May 2001. In Table 2, characteristics of infants are shown per age group. The mean age of the mothers and fathers was 31 and 34 years, respectively. The proportions of mothers and fathers with a low, middle and high level of education were $7 \%, 58 \%$ and $33 \%$ and $20 \%, 41 \%$ and $37 \%$, respectively. Mean value for parity was 1.7 . 
Table 2.

Characteristics of the study population by age (months)

\begin{tabular}{|l|l|l|l|l|l|l|}
\hline & $\mathbf{5 ~} \mathbf{~}$ & $\mathbf{7 ~} \mathbf{~}$ & $\mathbf{9 ~} \mathbf{~}$ & $\mathbf{1 1 ~} \mathbf{~}$ & $\mathbf{1 2 . 5} \mathbf{~ m}$ & Total \\
\hline Response (\%) & 20 & 20 & 17 & 19 & 13 & 18 \\
\hline Number of infants & 40 & 39 & 35 & 46 & 28 & 188 \\
\hline Boys (\%) & 55 & 62 & 51 & 43 & 57 & 53 \\
\hline Age (months) & $4.8(0.3)$ & $6.9(0.3)$ & $8.8(0.3)$ & $10.9(0.3)$ & $12.4(0.2)$ & $8.6(2.7)$ \\
\hline Age (weeks) & $20.9(1.2)$ & $29.9(1.5)$ & $38.2(1.4)$ & $47.3(1.3)$ & $53.9(0.8)$ & $37.3(11.7)$ \\
\hline Body weight (kg) & $6.9(0.8)$ & $8.1(0.9)$ & $8.7(0.8)$ & $9.7(1.0)$ & $10.3(1.1)$ & $8.7(1.5)$ \\
\hline Height (cm) & $64(3)$ & $68(3)$ & $71(2)$ & $74(3)$ & $77(3)$ & $71(5)$ \\
\hline
\end{tabular}

\section{2. $P C D D / F s$ and dioxin-like PCB exposure}

Fig. 1 shows the exposure of non-breastfed Dutch infants. Usual infant PCDD/F and dioxin-like PCB intake, based on information of two days, can be described by the function: $\log y=0.38-1.93 \times 0.92^{x}(x=$ age in weeks; $y=$ exposure in pg $\mathrm{TEQ} / \mathrm{kg} \mathrm{bw} \cdot \mathrm{d}$ ), according to the statistical exposure model (STEM). The median exposure to $\mathrm{PCDD} / \mathrm{F}$ and dioxin-like $\mathrm{PCB}$ is estimated for the younger infants of 4.8 months to be $1.1 \mathrm{pg} \mathrm{TEQ} / \mathrm{kg} \mathrm{bw} \cdot \mathrm{d}$ (95th percentile $1.7 \mathrm{pg} \mathrm{TEQ} / \mathrm{kg} \mathrm{bw} \cdot \mathrm{d}$ ). The median level of exposure increased to $2.3 \mathrm{pg} \mathrm{TEQ} / \mathrm{kg} \cdot \mathrm{d}$ (95th percentile $3.7 \mathrm{pg} \mathrm{TEQ} / \mathrm{kg} \mathrm{bw} \cdot \mathrm{d}$ ) in the older age group of 12.4 months.

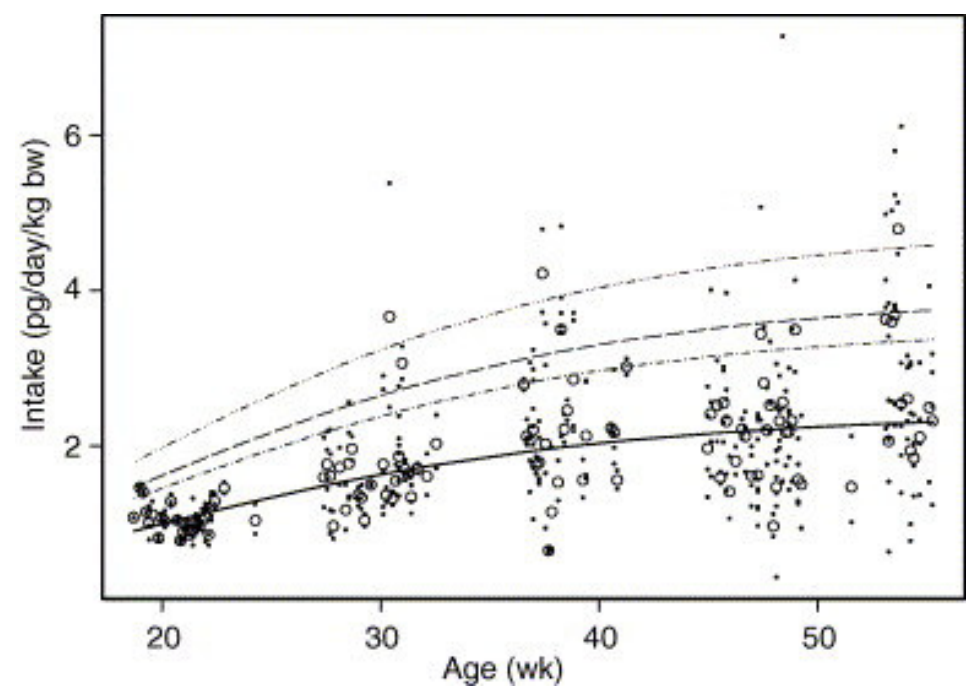

Fig. 1. Dioxin and dioxin-like PCB exposure of non-breastfed Dutch infants (pg $\mathrm{TEQ} / \mathrm{kg} \cdot \mathrm{d}$ ). Solid line is estimation of median exposure with fitted function; lines above solid line are the 90th, 95th and 99th percentile respectively. Dots are measured exposure for any recorded day, and open circles represent median value for any age group (per week).

Fig. 2 shows the fractional contribution of formula feeding and complementary foods to PCDD/F and dioxin-like PCB exposure. Exposure at 5 months originated 
mainly from formula feeding and the introduction of vegetables. At the age of seven months the introduction of meals from jars and a little meat contributed significantly to total PCDD/F and dioxin-like PCB intake. Subsequently, at the age of 9 and 11 months the contribution of milk and milk products as well as cheese increased, primarily at the expense of formula feeding. The contribution of meat and fish increased steadily with increasing age group. Although the contribution of vegetables appeared to decrease with age, from 6 months vegetables are often part of meals from jars. Just over 1 year of age the contribution of formula feeding is negligible. Fish showed a considerable contribution, with a very small number of users. Overall, the contribution of dairy (formula feeding) was $80 \%$ at the age of 5 months and dropped to $40 \%$ just after 1 year of age, with a larger variety of dairy products like milk products and cheese. The other $40 \%$ were obtained from meals in jars, meat and fish, as well as vegetables.

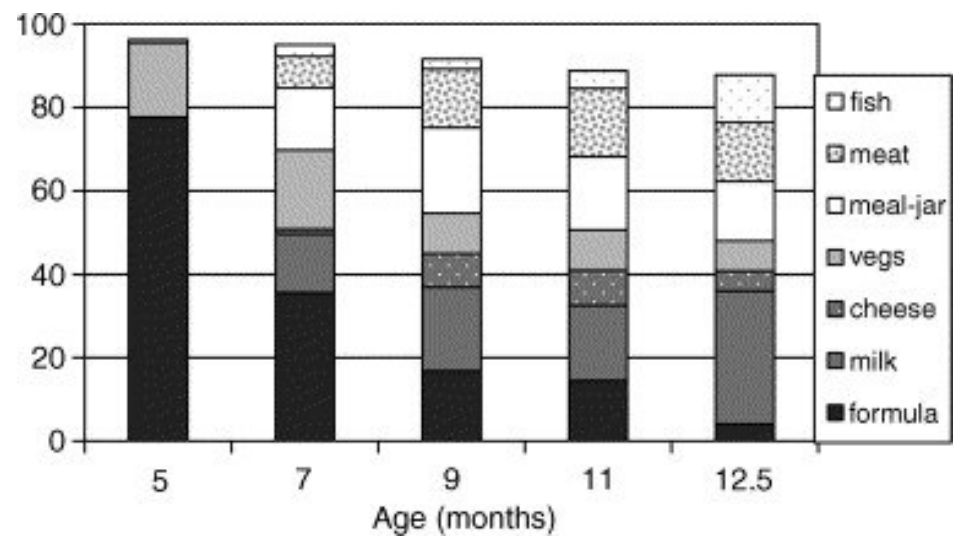

Fig. 2. Fractional contribution (\%) of formula feeding and complementary foods to dioxin and dioxin-like PCB exposure per age group.

As we only calculated the total TEQ taken in by the infants, we do not know the contribution of PCDD/Fs and dioxin-like PCBs respectively to the total intake. However, the ratio between PCDD/Fs and dioxin-like PCBs in dairy products, vegetable oil and meat is $\ldots 1.0-1.5$, while in fish it is about 1.6-2.23.

\section{Discussion}

To our knowledge this is the first study that estimates the PCDD/F and dioxin-like PCB exposure of non-breastfed Dutch infants. The median PCDD/F and dioxin-like PCB exposure, on the basis of bottle feeding and complementary foods, increased during the first year of life from $1.1 \mathrm{pg} \mathrm{TEQ} / \mathrm{kg} \cdot \mathrm{d}$ (95th percentile $1.7 \mathrm{pg}$ $\mathrm{TEQ} / \mathrm{kg} \cdot \mathrm{d}$ ) at 4.8 months to $2.3 \mathrm{pg} \mathrm{TEQ} / \mathrm{kg} \cdot \mathrm{d}$ (95th percentile $3.7 \mathrm{pg}$ $\mathrm{TEQ} / \mathrm{kg} \cdot \mathrm{d}$ ) just after the age of 1 year. A slightly higher value for median exposure of 12-24 months old non-breastfed infants has been described by Freijer et al. (2001) (median $3 \mathrm{pg} \mathrm{TEQ} / \mathrm{kg} \cdot \mathrm{d}$, 95th percentile $5.8 \mathrm{pg} \mathrm{TEQ} / \mathrm{kg} \cdot \mathrm{d}$ ). Schecter et al. (1994) reported for intake of $600 \mathrm{~g}$ soy formula per day, an estimated daily intake of only $0.07-0.16 \mathrm{pg} / \mathrm{kg} \cdot \mathrm{d}$. Our estimate for the less than 6 month old children is based on the lower bound PCDD/F and dioxin-like PCB concentration for the maize oil ingredient of infant formula $(0.19 \mathrm{pg} \mathrm{TEQ} / \mathrm{g}$ fat, Freijer et al., 2001), which is in line with the recently published lower bound value in the 1998 samples from the Food Standards Agency (2004a) (0.2 pg $\mathrm{TEQ} / \mathrm{g}$ fat). The Food Standards Agency (2004b) also published total average and upper bound intakes by babies of PCDD/Fs and dioxin-like PCBs from commercial baby foods of 0.2 and $0.7 \mathrm{pg} \mathrm{TEQ} / \mathrm{kg} \mathrm{bw} \cdot \mathrm{d}$, but infant formulae and noncommercial baby foods are not taken into account in these calculations. After 6 
months the intake via infant formula is low. Than, mainly the introduction of fresh dairy products and meat/fish caused an increase in the exposure of the nonbreastfed infants. The estimated intake of PCDD/Fs, which in the Netherlands only accounts for about half the intake of PCDD/F and dioxin-like PCB, is much higher for infants who consume breastmilk, as shown by Schecter et al. (1994) (35$53 \mathrm{pg} / \mathrm{kg} \cdot \mathrm{d})$, Brouwer et al. (1998) (133 pg/kg · d) and Hoover (1999) $(72 \mathrm{pg} / \mathrm{kg} \cdot \mathrm{d})$.

The study sample is relatively small, only about 50 infants per age group, but the geographical distribution of participants over the Netherlands is reasonably good. This sample probably underrepresents the lower education group. However, the educational level of parents was very similar to the only other recent Dutch investigation into dietary intake of infants, the Nutrient Intake Research (VIO) study (Netherlands Nutrition Centre, 2002). This study used a representative sample of 300 infants for both 9 and 12 month old. In general, a higher socioeconomic status corresponds to a lower fat intake, although differences do not appear to be very significant (Hulshof et al., 1991 and Hulshof et al., 2003). The possible effect of underrepresentation of the lower SES on PCDD/F and dioxin-like $\mathrm{PCB}$ exposure would be an underestimation. Especially when relatively less fat and very fat animal products like milk and milk products and meat, which are the main contributors of exposure in this study, are being used by the higher SES group. However, no comparable information on the effect of educational level on fat intake of non-breastfed infants is available.

The calculations of exposure are based on food intake and TEQ values for different foods. The National Institute of Health and Environment (RIVM) and the Institute of Food Safety (RIKILT) have estimated TEQ values for a large number foods per product code, as used in the Dutch Food Composition Table (NEVO). However, some specific infant products had to be estimated, by calculation from ingredients, for example infant formula's and meals in jars. Direct analysis of the TEQ value for the fat ingredient of different infant foods might further improve the exposure estimate.

The two day food diary was evaluated in practice, but the instrument was not validated. Since the VIO study also used a two day food record, a direct comparison for product and nutrient intake is made. The milk and meat consumption of 9 and 12 months old infants from the VIO study is very similar to our study. For instance, the mean use of milk and milk products in the 9-12 months old non-breastfed infants is about $600 \mathrm{ml} /$ day in either study.

The total fat intake of infants in our study of $30 \mathrm{gram}$ per day, was also very similar to the VIO study which found a fat intake of $31-34 \mathrm{~g} / \mathrm{d}$ for 9 and 12 months old Dutch non-breastfed infants (Netherlands Nutrition Centre, 2002). Fat intake values for younger age groups are not available. In the general Dutch population dietary fat intake has decreased between the Dutch National Food Survey (DNFS) of 1987-1988 and 1998 (Netherlands Nutrition Centre, 1998). Dietary fat intake has also slightly decreased in the youngest age group of 1-4 years between DNFS 1987-1988 and 1998 (52-50 for boys and 49-44 g for girls). If this trend can be translated to non-breastfed infants this has probably caused a decrease in fat intake over the past 15 years. Together with the observation that PCDD/F and dioxin-like PCB levels have decreased since the seventies (Baars et al., 2004), it is very likely that dietary PCDD/F and dioxin-like PCB exposure of Dutch non-breastfed infants has decreased over the past 15 years. The parents in this study provided $40 \%$ of total energy as fat for 5 months old and $30 \%$ of total energy as fat for the older age groups (Weijs et al., 2005), compared to the recommended percentage of $50 \%$ and $40 \%$ respectively (Health 
Council of The Netherlands, 2001). From this point of view there should be no further decrease in fat intake by Dutch non-breastfed infants, but an improvement in the quality of fat sources.

From our study it is concluded that non-breastfed Dutch infants also have a relatively high PCDD/F and dioxin-like PCB dietary exposure (expressed per kilogram body weight) compared to that of older children and adults. The current TDI for PCDD/F and dioxin-like PCB (2 pg/ $\mathrm{kg}$ bw - d) (Scientific Committee on Food, 2001) was exceeded by $5 \%$ of the infants at 5 months, $49 \%$ at 9 months and $64 \%$ of the 1 year old. In addition, infants may be a relatively sensitive group. On the other hand, the TDI has been defined on the basis of life long exposure, and a relatively short period of a higher exposure does not necessarily lead to adverse health effects, provided that the lifelong-average intake is lower than the TDI (Baars et al., 2004). Furthermore, compared to the intake of breastfed infants, the intake of PCDD/Fs and dioxin-like PCBs by formula-fed infants is low.

\section{Acknowledgements}

Acknowledgement for financial support: Ministry of Health, Welfare and Sports (Grant No. 3989 83-01) and acknowledgement of participating parents/caretakers. Tanja Braak en Brenda de Groot are appreciated for their contribution in the nutritional survey.

\section{References}

Baars et al., 2004 A.J. Baars, M.I. Bakker, R.A. Baumann, P.E. Boon, J.I. Freijer, L.A.P. Hoogenboom, R. Hoogerbrugge, J.D. van Klaveren, A.K.D. Liem, W.A. Traag and J. de Vries, Dioxins, dioxin-like PCBs and non-dioxin-like PCBs in foodstuffs: occurrence and dietary intake in The Netherlands, Toxicol. lett. 151 (2004), pp. 51-61.

Brouwer et al., 1998 A. Brouwer, U.G. Ahlborg, F.X.R. Van Leeuwen and M. Feeley, Report of the WHO working group on the assessment of health risks for human infants from exposure to PCDDs/PCDFs and PCBs, Chemosphere 37 (1998), pp. 1627-1643.

Donders-Engelen et al., 1997 M.R. Donders-Engelen, L. van der Heijden and K.F. A.M. Hulshof, Maten, gewichten en codenummers, Landbouwuniversiteit Wageningen, Wageningen (1997).

Food Standards Agency, 2004a Food Standards Agency, Dioxins and dioxin-like PCBs in infant formulae. Food Surveillance Information Sheet 49/04, Food Standards Agency, UK (2004).

Food Standards Agency, 2004b Food Standards Agency, Dioxins and dioxin-like PCBs in baby foods. Food Surveillance Information Sheet 60/04, Food Standards Agency, UK (2004).

Freijer et al., 2001 Freijer, J.I., Hoogerbrugge, R., Van Klaveren, J.D., Traag, W.A., Hoogenboom, L.A.P., Liem, A.K.D., 2001. Dioxins and dioxin-like PCBs in foodstuffs: occurence and dietary intake in The Netherlands at the end of the 20th century. Report No. 639102022. National Institute for Public Health and the Environment, Bilthoven, The Netherlands.

Hulshof et al., 1991 K.F. Hulshof, M.R. Lowik, F.J. Kok, M. Wedel, H.A. Brants, R.J. Hermus and F. ten Hoor, Diet and other life-style factors in high and low socio-economic groups (Dutch Nutrition Surveillance System), Eur. J. Clin. Nutr. 45 (1991), pp. 441-450. 
Hulshof et al., 2003 K.F. Hulshof, J.H. Brussaard, A.G. Kruizinga, J. Telman and M.R. Lowik, Socioeconomic status, dietary intake and 10 y trends: the Dutch National Food Consumption Survey, Eur. J. Clin. Nutr. 57 (2003), pp. 128-137.

Health Council of The Netherlands, 2001 Health Council of The Netherlands, 2001. Dietary Reference Intakes: energy, proteins, fats and digestible carbohydrates. Publication number 2001/19. Health Council of The Netherlands, The Hague.

Hoover, 1999 S.M. Hoover, Exposure to persistent organochlorines in Canadian breast milk: a propbabilistic assessment, Risk Analy. 19 (1999), pp. 527-545.

Netherlands Nutrition Centre, 1998 Netherlands Nutrition Centre, Zo eet Nederland 1998, Netherlands Nutrition Centre, The Hague (1998).

Netherlands Nutrition Centre, 2002 Netherlands Nutrition Centre, Zo eten jonge peuters in Nederland 2002. Resultaten van het Voedingsstoffen Inname Onderzoek 2002, Netherlands Nutrition Centre, The Hague (2002).

NEVO Foundation, 2001 NEVO Foundation, 2001. Dutch Food Composition Table. Netherlands Nutrition Centre, The Hague.

Schecter et al., 1994 A. Schecter, J. Startin, C. Wright, M. Kelly, O. Päpke, A. Lis, M. Ball and J.R. Olson, Congener-specific levels of dioxins and dibenzofurans in US food and estimated daily dioxin toxic equivalent intake, Eviron. Health Perspect. 102 (1994), pp. 962-966.

Scientific Committee on Food, 2001 Scientific Committee on Food, 2001. Opinion of the SCF on the risk assessment of dioxins and dioxin-like PCBs in food. Update based on new scientific information available since the adoption of the SCF opinion of 22nd November 2000. European Commission, Brussels.

Slob, 1993 W. Slob, Modeling long-term exposure of the whole population to chemicals in food, Risk Anal. 13 (1993), pp. 525-530.

Van den Berg et al., 1998 M. Van den Berg, L. Birnbaum, B.T.C. Bosveld, B. Brunström, P. Cook, M. Feeley, J.P. Giesy, A. Hanberg, R. Hasegawa, S.W. Kennedy, T. Kubiak, J.C. Larsen, F.X.R. van Leeuwen, A.K.D. Liem, C. Nolt, R.E. Peterson, L. Poellinger, S. Safe, D. Schrenck, D. Tillitt, M. Tysklind, M. Younes, F. Waern and T. Zacharewski, Toxic equivalency factors (TEFs) for PCBs, PCDDs, PCDFs for humans and for wildlife, Environ. Health Perspect. 106 (1998), pp. 775-792.

Van Leeuwen et al., 2000 F.X.R. Van Leeuwen, M. Feeley, D. Schrenk, J.C. Larsen, W. Farland and M. Younes, Dioxins: WHO's tolerable daily intake (TDI) revisited, Chemosphere 40 (2000), pp. 10951101.

Weijs et al., 2005 P.J.M. Weijs, R. Korver, T. Braak and B. de Groot, Protein intake is very high in nonbreastfed Dutch infants 4-12 months of age, Clinical Nutrition 24 (2005), p. 577.

* Corresponding author. Tel.: +3120 5953534; fax: +31205953445. 